\title{
A Multilevel Bayesian Markov Chain Monte Carlo Poisson Modelling of Factors Associated With Number of Components of Antenatal Care Offered Pregnant Women In Nigeria
}

Adeniyi Francis Fagbamigbe ( $\nabla$ franstel74@yahoo.com )

University of Ibadan

Omon Stellamaris Fagbamigbe

University of Portsmouth

Olugbenga Sunday Olaseinde

Adekunle Ajasin University

Oluwasomidoyin 0. Bello

University of Ibadan

Vincent Sethare

University of Botswana

Jackline Mosinya Nyaberi

Jomo Kenyatta University of Agriculture and Technology

Research Article

Keywords: Antenatal care, Nigeria, WHO guidelines, ANC contacts, supplements, quality of care, ANC components

Posted Date: June 11th, 2021

DOI: https://doi.org/10.21203/rs.3.rs-578328/v1

License: (c) (i) This work is licensed under a Creative Commons Attribution 4.0 International License. Read Full License 


\section{Abstract}

Background: The most recent WHO guideline on antenatal care (ANC) utilization reaffirmed the necessary and compulsory care and services a pregnant woman should receive to maximize the importance and gains of ANC. While most studies focused on the time of initiation and number of ANC contacts, emphasis was rarely placed on the components of ANC offered women. This study assessed the number of components of ANC received by pregnant women as a proxy for the quality of ANC services offered in Nigeria. We also assessed the clustering of the components and within-country differentials and inequalities in the components of ANC received in Nigeria.

Methods: We used nationally representative cross-sectional data from the 2018 Nigeria Demographic Health Survey. We analysed data of 11867 women who had at least one ANC contacts during the most recent pregnancy within five years preceding the survey. The assessed components were tetanus injection, blood pressure, urine test, blood test, iron supplement, malaria intermittent preventive treatment in pregnancy (IPTp), and told about danger signs. Others are intestinal parasite drugs (IPD)intermittent and HIV/PMTCT counsel. Descriptive statistics, bivariable and multivariable multilevel Bayesian Monte Carlo Poisson model were used.

Results: In all, 94\% had blood pressure measured, 91\% received tetanus injection, had iron supplement$89 \%$, blood test- $87 \%$, urine test- $86 \%$, IPTp- $24 \%$, danger signs- $80 \%$, HIV/PMTC-82\% and IPD-22\%. The overall prevalence of receiving all 9 components was $5 \%$ and highest in Ogun (24\%) and lowest in Kebbi $(0.1 \%)$. The earlier the initiation of ANC, the higher the number of contacts, and the higher the quality of ANC received. Respondents with higher education have 4\% (adjusted incidence risk ratio (alRR): 1.04, 95\% credible interval (Crl): 1.01-1.09) higher risk of receiving more components of ANC relative to those with no education. The risk of receiving more ANC components were $5 \%$ (aIRRR: $1.05,95 \% \mathrm{Cl}$ : 1.01-

1.10) higher among pregnant women aged 40 to 49 years than those aged 15 to 19 years. Women who decide their healthcare utilization alone had $2 \%$ higher risk of getting more components than those whose spouses are the only decision taker of health care use. Other significant factors were household wealth status, spouse education, ethnicity, place of ANC, and skill of ANC provider. Pregnant women who had their blood pressure measured were very likely to have blood and urine tests, tetanus injection, iron supplement, and HIV talks.

Conclusions: Only one in every 20 pregnant women received all the 9 ANC components with wide disparities and inequalities across the background characteristics and the States of residence in Nigeria. There is a need to ensure that all pregnant women receive adequate components. Stakeholders should increase supplies, train, and create awareness among ANC providers and pregnant women in particular.

\section{Introduction}

Although improvements have been recorded in maternal and child health globally, most developing countries in sub-Saharan Africa (SSA) have continued to lag in the pace of this improvement [1]. Most 
maternal and child health indicators put the Low and Middle-Income Countries (LMIC) including Nigeria at the lower end of the scale [1]. The Maternal and Child Health $(\mathrm{MCH})$ situation in the SSA remained worrisome when compared to the advanced countries and some other developing countries. A childbearing woman in the developed countries has 1 in 5,400 chance of dying from pregnancy and childbirth-related complications compared with only 1 in 22 chances in SSA [1].

To facilitate the attainment of Sustainable Development Goals (SDGs) on improved health and wellbeing [2], in its Strategy for Health 2016 to 2030, the UNICEF envisioned "a world where no child dies from a preventable cause and all children reach their full potential in health and wellbeing" [3]. Efforts focused on achieving this vision birthed the goal to "end preventable maternal, newborn and child deaths" [3]. This underscores the need to ensure guaranteed maternal and child health without inequality at any level. Antenatal care (ANC) is recognised worldwide as the main approach to ensure safe maternal and infant health outcomes. Compliance with ANC protocol is important in the management of pregnancy conditions and is essential for safe delivery [4-7]. The standards in the existing ANC protocol were reviewed in 2016 to reinvigorate the ANC program to guarantee the realization of the relevant goal of the SDGs by 2030 [7]. The reviewed WHO guideline on ANC utilization established three main pillars that can help maximize the gains and importance of ANC utilization. They are (i) initiation of first ANC contact in the first trimester of gestation (ii) having a minimum of 8 ANC contacts and (iii) receiving all components of ANC during the contacts with ANC providers. Therefore, it is not just sufficient to initiate ANC early and have at least 8 ANC contacts, a pregnant women must receive all the components of ANC services. WHO therefore prescribed the components of ANC to achieve effective results all over the world [7]. Thus, among other reviewed standards, several services were packaged to make up the minimum quality of ANC available to a pregnant woman. Emphasis was laid on the compulsory administration of specific components of ANC [7]. WHO identified and grouped the components to ensure standard quality of ANC into three (i) history taking, assessment, physical examination and laboratory tests, (ii) health promotion and education on nutrition, delivery, danger signs, child health and (iii) care provision such as tetanus toxoid immunization, and others[7-10]. The specifics of these components vary slightly across countries.

Although evidence supports that ANC coverage has increased in Nigeria [11-14], improvement in coverage alone cannot guarantee safe maternal and infant health outcomes $[15,16]$. A Nigerian study showed evidence of an unacceptable quality of ANC with only about 1 in 8 pregnant women who had ANC contacts were provided with the minimum quality standard [15]. The study further emphasized that the poor quality of ANC among childbearing women might have contributed to the non-realisation of the defunct Millennium Development Goals (MDGs) on child and maternal health in Nigeria.

Early initiation of ANC, sufficient number of ANC contacts, attention by skilled health workers, living in urban areas, better education, short distance to health facilities, media exposure, and household wealth quintile have been associated with the quality of ANC received by pregnant women in Nigeria [15, 17-19]. Older pregnant women, higher parity, higher level of education, and higher household wealth status were identified as factors associated with receiving a good quality of ANC by a similar study in Nepal [18]. Also, a Kenyan study pointed out that level of women's literacy, employment status, and receiving all ANC 
services from a health facility had a relationship with having a good quality of ANC by pregnant women $[20,21]$. Studies have identified that the commonest components of ANC services received by pregnant women were blood pressure measurement, iron supplement, urine test $[15,20]$; while education on PMTCT was low in Nigeria as only 2 in 5 tested for HIV during ANC visit [15] and negligible proportion had an ultrasound performed.

While most studies focused on the time of initiation of ANC contacts and the minimum number of ANC contacts made, such emphasis was rarely placed on the components of ANC offered women during the ANC contacts. Whereas, up to date information on the components of ANC services could provide a good understanding of the level of compliance with the recommended components and standards of ANC in Nigeria and could provide relevant evidence-based information necessary to inform policy on the implementation of the WHO ANC guidelines. This study is also a response to the United Nations call for periodical monitoring and evaluation of how close countries of the world are to attaining the specific targets of the Sustainable Development Goals (SDG) [2]. The call also encouraged sub-country analysis. Our study shows how close Nigeria is to SDG-3 target 3.1: "By 2030, end preventable deaths of newborns and children under 5 years of age, with all countries aiming to reduce neonatal mortality to at least as low as 12 per 1,000 live births and under- 5 mortality to at least as low as 25 per 1,000 live births" [2]. The services received during ANC contacts are of paramount importance to the attainment of SDG-3.

Therefore, this study assessed the number of components of ANC received by pregnant women in Nigeria and its associated factors. We also assessed within-country differentials and inequalities in the quality of ANC care across the states in Nigeria and examined clustering of the ANC components (or its lack) to inform policy intervention and research translation. The study provided recommendations on the pathways for the improvement of maternal and child health outcomes in Nigeria.

\section{Methodologies}

\section{Study Setting and Data Source}

The study was retrospective and cross-sectional in design. Data were extracted from the nationally representative 2018 Nigeria Demographic Health Survey (NDHS) conducted by ICF Macro Calverton, Maryland, USA in conjunction with the Nigeria National Population Commission (NPC), Nigeria [13]. Administratively, Nigeria is divided into 36 states and the Federal Capital Territory (FCT). The states are further grouped into 6 regions as shown in Fig. 1. Although the regions have no administrative functions, people within each region are deemed to have similar characteristics, culture, ethnicity, vegetation etc. Each state is subdivided into local government areas (LGAs). Using the most recent 2006 Population Census, each LGA was subdivided into convenient areas called census enumeration areas (EAs).

\section{Sampling Techniques}

A two-stage probability sampling was adopted to select the respondents who were women of childbearing age (15-49). The EAs were the primary sampling unit (PSU). In each state, depending on the population, about 38 EAs were selected with probability proportional to EA size making a total of 1,400 
EAs in the first stage. Then a full list of households in all selected EAs in the first stage was drawn to serve as the sampling frame for household selection in the second stage. In the second stage, 30 households each were selected in every EAs using equal probability systematic sampling. All eligible women of reproductive age (15-49 years) in each selected household were interviewed. Due to the nonproportional allocation of sample sizes at the different states, LGAs and EAs, as well as the possible differences in response rates, sampling weights were applied in all the descriptive analysis. A total of 41,821 women aged 15-49 years were interviewed [13].

\section{The Data}

All respondents (women aged 15-49 years) were asked if they had any pregnancy or birth within 5 years preceding the survey (2013 to 2018). Those who had at least one birth were thereafter asked questions relating to conception, pregnancy-related care including ANC visits made, time ANC began, ANC care provider, etc of each birth delivery starting from the most recent. Our analysis is based on the information provided on the most recent deliveries and the associated pregnancy information. Among the 21,785 women who provided information about the ANC visits during their most recent pregnancy within the five years that preceded the survey, $16,448(75.5 \%)$ made at least one ANC visit. We used all pregnancy history from 2013 to 2018 because the 2016 WGO guideline only reaffirmed the preceding guidelines in the 1990s, and 2006. Furthermore, of those that had at least one ANC contact, only $11867(72.1 \%)$ provided the ANC components received during all ANC contacts for the most recent pregnancy. Our analysis was based on the components of ANC received by the 11867 women.

\section{Variables}

The outcome variable in this study is the quality of ANC services using the number of ANC components received as a proxy. The identified components were: receiving tetanus injection, intestinal parasite drugs (IPD), blood pressure, urine test, blood test, iron supplement, three or more doses of malaria intermittent preventive treatment in pregnancy (IPTp), told about danger signs, and counselled on HIV/PMTCT (either talked about HIV transmitted mother to child, things to do to prevent getting HIV, getting tested for HIV). These components have been recommended and recognized in the literature $[7,8,15,18,20,22]$.

\section{Conceptual framework}

Having ANC components could be influenced women and their household compositional factors as well as the contextual based on community and state of residence and the health system. These include women and their spouse background characteristics, their employment status, and household wealth status that could determine the type of facilities women patronize. Similarly, the birth order and preceding birth interval, as well as family mobility, could affect health care utilization. Due to the secondary nature of the data used, the health system factors considered in this study are having health insurance, the skill of the ANC provider and whether the ANC was received at a health facility or not. Having health insurance could dictate the type of health facility visited and by extension the skill of the ANC providers which are major influencers of giving ANC components to women. Of importance are the community factors (such 
as poverty level, illiteracy, rural residence, poor media access) and societal factors such as religion and ethnicity as they could affect the uptake of components.

Based on existing literature $[15,17,20,21,23,24]$, the independent variables are maternal age (15$19,20-24,25-29,30-39,40-49$ years), education (no education, primary, secondary and higher), spouse education (no education, primary, secondary and higher), employment status (currently employed or not), spouse employment status (currently employed or not), access to media (at least one of radio, television, or newspaper), household wealth tertiles (lowest, middle, and highest), women's autonomy using "who decides respondents health care" (respondent alone, respondent/spouse, and spouse alone) as a proxy. Others are birth interval (firstborn, $<36$ months, and $>=36$ months), birth order (1, 2, 3, 4 and 5+), children ever born (none, 1-2, 3-4,4+), current marital status (currently married or living together, divorced/separated/widowed, never married), place of residence (rural/urban), religion (Islam, Christian, others), and ethnicity (Hausa/Fulani, Igbo, Yoruba, and others). Family mobility (had stayed less than five years at residence or not), wanted child when became pregnant (then, later or not more), household headship (male or female), health insurance coverage (yes or no), place of ANC (health institution or not) and ANC caregiver (skilled or unskilled).

We also assessed four community-level factors in the descriptive analysis: poverty rate (high or low), unemployment rate (high or low), illiteracy rate (high or low), and media access rate (high or low). The communities are synonymous with the EAs. We computed the community socioeconomic (SES) disadvantage composite score using principal component analysis of the proportion of respondents within each community with no media access, who are illiterates, who are poor, and who are unemployed. The SES was categorized into three tertiles: lowest, middle, and highest. The only state-level characteristics considered was the proportion of the rural population in the states of residence. It was categorised as low rural proportion (0-33.3\%); medium rural proportion $(33.4-66.7 \%)$ and high rural proportion (66.8-100\%).

\section{Statistical Methods}

Data were analysed using descriptive statistics, bivariable, and multivariable logistic regression using STATA version 16 (Stata Corp, Texas, USA). We invoked the "SVY" command in STATA to adjust for the study design and the sampling weights. Frequency tables showing percentages were used to describe the distribution of study respondents' characteristics and the distribution of outcome variables by the respondents' characteristics (Tables 1 ).

We fitted a multilevel Bayesian Markov Chain Monte Carlo (MCMC) Poisson-based Generalized Linear Model (GLMs) to the data, with women nested within EAs and the EAs nested within the states. The models have mixed outcomes consisting of the fixed and random parts as shown in Eq. (1).

$$
\log \left(\gamma_{i j k}\right)=\underbrace{\beta_{0}+\sum_{p=1}^{t} \beta_{p} X_{p i j k}}_{\text {Fixed }}+\underbrace{U_{0 j k}+V_{0 k}}_{\text {Random }}
$$


The "risk" that pregnant woman $i$ of community $j$ from state $k$ will receive ANC component is denoted by $Y_{i j k} \mathrm{U}_{o j k}$ is the random effect of mothers community $j$ in state $k$ and $\mathrm{V}_{\mathrm{ok}}$ is the random effect of state $k$, $e_{i j k}$ is the noise such that $e_{i j k} \sim N\left(0, \sigma_{e}^{2}\right), U_{o j k} \sim N\left(0, \sigma_{U}^{2}\right)$ and $V_{o k} \sim N\left(0, \sigma_{V}^{2}\right)$ in a model with $t$ covariates.

We reported the measure of the rates of receiving the components as incidence rate ratios (IRRs) with their $95 \%$ credible intervals (Crl). Measures of variations were explored using the intraclass correlation (ICC) and median incidence rate ratios (MIRR) $[25,26]$. The ICCs, an equivalent of the variance partition coefficient (VPC), is the percentage of the total variance in the risk of a pregnant woman obtaining the components that is related to the community and state where they live (i.e. a measure of clustering of risk of child mortality in the same community and state). We also estimated the proportion of total variance which are accounted for at the community $\left[\sigma_{U}^{2} /\left(\sigma_{U}^{2}+\sigma_{V}^{2}+\sigma_{e}^{2}\right)\right]$ and the state $\left[\sigma_{V}^{2} /\left(\sigma_{U}^{2}+\sigma_{V}^{2}+\sigma_{e}^{2}\right)\right]$ levels. The MIRR is the estimate of the probability that a pregnant woman will receive additional components attributable to the community and state context. The Bayesian MCMC Multilevel Poisson model was implemented using MLwin v3.03 and implemented in Stata V16 with the following parameters: Burnin = $5000 ;$ Chain $=50000$, Thinning $=50$.

At the bivariable level, we first identified all variables that were significant at $p<0.20$. The identified independent variables were then used as candidate variables in the multivariable model from where we identified the adjusted odds ratios of characteristics associated with the quality of ANC services. The "collin" command in Stata was used to identify collinear variables and the associated variance Inflation factor (VIF). Based on the VIF, the less important of a pair of collinear variables were dropped from the multiple regression. We used the principal component (PCA) and factor analysis procedure to explore clustering among the components. The PCA method maintains all theoretically relevant variables and avoids the negative influence of high inter-correlation among the variables [27, 28]. The "cluster singlelinkage" and "loadingplot" commands in Stata were used to analyze the data and visualize the clustering respectively.

\section{Ethics approval}

This study was based on the analysis of existing survey data. The Institutional Review Board (IRB) of ICF Macro at Fairfax, Virginia in the USA reviewed and approved the MEASURE Demographic and Health Surveys Project Phase III. The 2010-2018 DHS's are categorized under that approval. The IRB of ICF Macro complied with the United States Department of Health and Human Services requirements for the "Protection of Human Subjects" (45 CFR 46). Written informed consent was obtained from every study participant before participation and all information was collected without identifiers and kept confidentially. The full details of the ethical approvals can be found at http://dhsprogram.com.

\section{Results}

In all, 11867 women provided information about the ANC components received during ANC visits for their most recent pregnancy during the 5 years preceding the survey. During the last pregnancy, $94 \%$ had their 
blood pressure measured, nine of every ten women (91\%) received tetanus injection, $89 \%$ were given an iron supplement, $87 \%$ had a blood test, $86 \%$ had a urine test, $82 \%$ received counselling on HIV/PMTC, $80 \%$ were told about danger signs while only $24 \%$ got IPTp and only $22 \%$ received IPD (Fig. 2).

Figure 3 shows that only $5 \%$ of the respondents received all the 9 components (Fig.3). The commonest (35\%) number of components received was 7 . About $61 \%$ and $90 \%$ received at least 7 and at least 5 components respectively.

Table 1 shows the distribution of the respondents by their background characteristics and the prevalence of receiving all the 9 studied components. The prevalence of having the 9 components was highest (6\%) among women aged 30 to 39 years compared with $2 \%$ among those aged 15 to 19 years. Nearly a quarter $(10 \%)$ of the pregnant women with higher education who had at least one ANC contact received all the 9 ANC components while less than $2 \%$ of those with no education did. The proportion of all the 9 ANC components was lowest among women whose spouse alone decide health care access (3\%), no media exposure (2\%), Hausa/Fulani (2\%), form low wealth households (2\%), North East (3\%) North West $(2 \%)$ and from rural areas (4\%) as shown in Table 1. All the explanatory variables considered were significantly $(p<0.001)$ associated with receiving all the ANC components received except whether the pregnancy was wanted or not and the type of ANC facility attended. Also, all characteristics in Table 1 were associated with having all 9 components, except marital status, sex of household head, whether the pregnancy was wanted or not, health insurance, community media access. Having all the components was significantly higher among women from communities with low rates of illiteracy, poverty, and community socioeconomic disadvantage. 
Table 1

Respondents' Characteristics and having all ANC components during the most recent pregnancy

\begin{tabular}{|c|c|c|c|}
\hline \multirow[t]{2}{*}{ Characteristics } & \multirow[t]{2}{*}{$\mathrm{n}(\%)$} & \multicolumn{2}{|c|}{ Received All 9} \\
\hline & & $\%$ & p-value \\
\hline Age of mothers & & & 0.004 \\
\hline $15-19$ & $705(6.0)$ & 2.0 & \\
\hline $20-24$ & $2569(21.7)$ & 4.1 & \\
\hline $25-29$ & $3314(27.9)$ & 5.3 & \\
\hline $30-39$ & $4420(37.2)$ & 6.0 & \\
\hline $40-49$ & $856(7.2)$ & 5.4 & \\
\hline Highest educational level & & & 0.000 \\
\hline No education & $4057(34.2)$ & 1.6 & \\
\hline Primary & $1902(16.0)$ & 5.2 & \\
\hline Secondary & $4587(38.7)$ & 6.9 & \\
\hline Higher & $1320(11.1)$ & 9.6 & \\
\hline Spouse's highest education & & & 0.000 \\
\hline No education & $2828(25.3)$ & 1.1 & \\
\hline Primary & $1631(14.6)$ & 5.0 & \\
\hline Secondary & $4494(40.2)$ & 6.4 & \\
\hline Higher & 2209(19.7) & 7.3 & \\
\hline Who decides respondent's healthcare & & & 0.000 \\
\hline Respondent alone & $1176(10.5)$ & 6.6 & \\
\hline Respondent and Spouse & $3937(35.1)$ & 7.0 & \\
\hline Spouse alone & $6093(54.4)$ & 3.4 & \\
\hline Media exposure & & & 0.000 \\
\hline Unexposed to media & $3519(29.7)$ & 1.9 & \\
\hline Exposed to media & $8348(70.3)$ & 6.5 & \\
\hline Ethnicity & & & 0.000 \\
\hline Hausa/Fulani & 4668(39.3) & 1.6 & \\
\hline
\end{tabular}




\begin{tabular}{|c|c|c|}
\hline Characteristics & $n(\%)$ & Received All 9 \\
\hline Yoruba & $1680(14.2)$ & 12.9 \\
\hline Igbo & $2050(17.3)$ & 8.5 \\
\hline Others & $3468(29.2)$ & 4.1 \\
\hline Religion & & 0.000 \\
\hline Islam & $6750(56.9)$ & 3.4 \\
\hline Other Christians & $5064(42.6)$ & 7.6 \\
\hline Others & $53(0.5)$ & 0.0 \\
\hline Marital Status & & 0.385 \\
\hline Never married & $267(2.3)$ & 10.4 \\
\hline Living with a spouse & $11280(95.1)$ & 5.0 \\
\hline Widowed/Divorced/Separated & $320(2.7)$ & 6.4 \\
\hline Household Wealth status & & 0.000 \\
\hline Lowest & $2834(23.9)$ & 1.7 \\
\hline Middle & $3925(33.1)$ & 4.0 \\
\hline Richest & $5107(43.0)$ & 9.0 \\
\hline Children ever-born & & 0.001 \\
\hline 1 or 2 births & $4260(38.9)$ & 6.0 \\
\hline 3 or 4 births & $3424(28.9)$ & 6.2 \\
\hline More than 4 births & $3822(32.2)$ & 3.2 \\
\hline Birth order & & 0.000 \\
\hline First & $2315(19.5)$ & 6.6 \\
\hline Second & $2305(19.4)$ & 5.4 \\
\hline Third & $1903(16.0)$ & 6.4 \\
\hline Fourth & $1521(12.8)$ & 5.9 \\
\hline Fifth or higher & $3822(32.2)$ & 3.2 \\
\hline Birth interval & & 0.001 \\
\hline First birth & $2315(19.5)$ & 6.6 \\
\hline$<36$ months & $5520(46.6)$ & 4.1 \\
\hline
\end{tabular}




\begin{tabular}{|c|c|c|}
\hline Characteristics & $n(\%)$ & Received All 9 \\
\hline$>=36$ months & $4013(33.9)$ & 5.8 \\
\hline Current employment status & & 0.000 \\
\hline Employed & $8346(70.3)$ & 6.1 \\
\hline Unemployed & $3521(29.7)$ & 2.9 \\
\hline Spouse current employment statement & & 0.000 \\
\hline Employed & $8846(74.5)$ & 5.9 \\
\hline Unemployed & $3021(25.5)$ & 2.8 \\
\hline Household sex & & 0.110 \\
\hline Male & 10716(90.3) & 5.0 \\
\hline Female & $1151(9.7)$ & 6.3 \\
\hline Wanted Last child & & 0.738 \\
\hline Then & 10338(87.1) & 5.1 \\
\hline Later & 1177(9.9) & 5.4 \\
\hline Never & $352(3.0)$ & 4.1 \\
\hline Family Mobility & & 0.019 \\
\hline $5+y r$ & $9561(80.6)$ & 4.9 \\
\hline Less stable 0-4yr & $2305(19.4)$ & 6.3 \\
\hline Have health Insurance & & 0.223 \\
\hline No & 11563(97.4) & 5.1 \\
\hline Yes & $304(2.6)$ & 7.0 \\
\hline Place of antenatal care & & 0.026 \\
\hline Non-health facility & $439(3.7)$ & 1.9 \\
\hline Health facility & $11428(96.3)$ & 5.3 \\
\hline Provider of ANC assistance & & 0.000 \\
\hline Unskilled provider & $1724(14.5)$ & 1.5 \\
\hline Skilled provider & 10143(85.5) & 5.7 \\
\hline No of ANC Visits & & 0.000 \\
\hline $1-3$ & $2859(24.4)$ & 2.0 \\
\hline
\end{tabular}




\begin{tabular}{|c|c|c|}
\hline Characteristics & $\mathrm{n}(\%)$ & Received All 9 \\
\hline $4-7$ & $5960(51.0)$ & 4.8 \\
\hline $8+$ & $2872(24.6)$ & 7.6 \\
\hline First ANC Visit & & 0.000 \\
\hline Trimester 1 & $2805(23.7)$ & 8.2 \\
\hline Trimester 2 & $7432(62.7)$ & 4.6 \\
\hline Trimester 3 & 1611(13.6) & 2.4 \\
\hline Region & & 0.000 \\
\hline North central & $1420(12.0)$ & 4.5 \\
\hline North East & $2143(18.1)$ & 3.1 \\
\hline North West & $3770(31.8)$ & 1.5 \\
\hline South East & $1478(12.5)$ & 8.3 \\
\hline South South & $1112(9.4)$ & 5.8 \\
\hline South West & $1945(16.4)$ & 12.2 \\
\hline Residence & & 0.000 \\
\hline Urban & $5458(46.0)$ & 6.6 \\
\hline Rural & $6409(54.0)$ & 3.9 \\
\hline Community Poverty Rate & & 0.001 \\
\hline High & $4863(41.0)$ & 3.7 \\
\hline Low & $7004(59.0)$ & 5.8 \\
\hline Community Illiteracy & & 0.000 \\
\hline High & 4967(41.9) & 3.3 \\
\hline Low & $6900(58.1)$ & 5.9 \\
\hline Community Unemployment & & 0.007 \\
\hline High & $5226(44.0)$ & 4.1 \\
\hline Low & $6641(56.0)$ & 5.8 \\
\hline Community Media barrier & & 0.167 \\
\hline High & $5817(49.0)$ & 4.6 \\
\hline Low & $6049(51.0)$ & 5.5 \\
\hline
\end{tabular}




\begin{tabular}{|lll|}
\hline Characteristics & $\mathbf{n}(\%)$ & Received All $\mathbf{9}$ \\
\hline Community SES Disadvantage & & \multicolumn{2}{c|}{$\mathbf{0 0 0}$} \\
\hline Lowest & $4807(40.5)$ & 9.7 \\
\hline Middle & $4296(36.2)$ & 4.0 \\
\hline Highest & $2764(23.3)$ & 1.3 \\
\hline Total & 11867 & 5.1 \\
\hline Significance at $\chi^{2}, \mathbf{0 . 0 5}$ & & \\
\hline
\end{tabular}

Figure 4 shows the map of Nigeria with the geographical distribution of the percentage of ANC attendees that received all the nine components across the states. The highest prevalence of receiving all the 9 studied components was highest in Abia (32\%), none (0\%) in Zamfara, Borno (0.1\%) and Kebbi $(0.3 \%)$. Benue (8.3\%), Kwara (8.6\%) and Adamawa (9.3\%) are the only states in the North with at least $5 \%$ women receiving all the 9 components. The only five states with $10 \%$ or higher were from the southern part of Nigeria. The distribution of having all ANC component received during the most recent pregnancy by States and regions in Nigeria is shown in Supplementary Table A.

\section{Relationship between the number of ANC contacts, the timing of first ANC contact, and receiving all 9 ANC components received in Nigeria}

The number of ANC contacts made during the last pregnancy and the timing of the first ANC contact were both significantly associated with the adequacy of ANC components received (Table 1 and Fig. 5). Figure 5 shows that a linear association exists between the number of ANC contacts made, the timing of the first ANC contacts, and the adequacy of ANC care received. Pregnant women who had first ANC contact during the first trimester had a higher (8\%) prevalence of having all 9 components than those who started in the third trimester (2\%). Similarly, pregnant women who had 8 or more ANC contact had a higher ( $8 \%$ ) prevalence of having all 9 components than those who had less than 4 contacts $(2 \%)$.

\section{Factors associated with the number of ANC Components Received}

Table 2 shows the crude and adjusted risk of receiving additional components of ANC among the respondents from the multilevel Bayesian MCMC Poisson model. The five-way MCMC graphical diagnostics of model 5 at the community and state levels are presented in Figs. 6 and 7 respectively. Respondents with higher education have 4\% (adjusted incidence risk ratio (alRR): 1.04, $95 \%$ confidence interval (CI): 1.01-1.09) higher risk of receiving more components of ANC relative to those with no education (Table 2). The risk of receiving more ANC components were $5 \%$ (alRR: 1.05, 95\% Cl: 1.01-1.10) higher among pregnant women aged 40 to 49 years than those aged 15 to 19 years. Women who decide their healthcare utilization alone had $2 \%$ higher risk of getting more components than those whose spouses are the only decision taker of health care use. Pregnant women from in South East were 6\% more likely to receive a higher number of components of ANC relative to those in the North West. Also, 
respondents from the households in the richest wealth quartile were $3 \%$ more likely to receive a higher number of components of ANC relative to those from households in the low wealth category. The risk of having a higher number of components was $4 \%$ higher in communities with the lowest SES disadvantaged than those with the highest disadvantage. Other significant variables with having a higher number of components of ANC are spouse education, ethnicity, religion, respondent's current employment status, family mobility, having health insurance, place of ANC, and skill of ANC provider, the proportion of the rural population in the states of residence. 
Table 2

Crude and Adjusted correlates of number of ANC components received during the most recent pregnancy (NDHS 2018)

\begin{tabular}{|lllll}
\hline Characteristics & IRR(95\% Cl) & significance & alRR(95\% Cl) & significa \\
\hline Fixed Effects & & & & \\
\hline Age of mothers & & & & \\
\hline $15-19$ & Reference & & & \\
\hline $20-24$ & $1.05(1.02-$ & $\mathbf{0 . 0 0 3}$ & $1.03(0.98-$ & 0.096 \\
& $1.09)$ & & $1.07)$ & \\
\hline $25-29$ & $1.09(1.05-$ & $\mathbf{0 . 0 0 0}$ & $1.04(0.99-$ & $\mathbf{0 . 0 4 5}$ \\
& $1.13)$ & & $1.09)$ & \\
\hline $30-39$ & $1.09(1.06-$ & $\mathbf{0 . 0 0 0}$ & $1.04(1.01-$ & $\mathbf{0 . 0 3 8}$ \\
& $1.13)$ & & $1.09)$ & \\
\hline $40-49$ & $1.08(1.03-$ & $\mathbf{0 . 0 0 1}$ & $1.05(1.01-$ & 0.045 \\
& $1.12)$ & & $1.10)$ & \\
\hline
\end{tabular}

Highest educational level

No education

Reference

Primary

$1.06(1.04-$

1.09)

0.000

1.01(0.98-

0.300

Secondary

1.14(1.12-

1.16)

0.000

1.04)

$1.20(1.17-$

1.23)

1.04(1.01-

1.07)

Higher

0.000

1.04(1.01-

1.09)

\section{Spouse's highest education}

No education

Reference

Primary

1.08(1.05-

1.11)

0.000

1.03(1.01-

1.05)

Secondary

1.15(1.12-

1.17)

0.000

1.05(1.02-

1.08)

Higher

$1.18(1.15-$

1.21)

0.000

1.05(1.02-

1.08)

0.010

0.024

Who decides respondent's

healthcare

\begin{tabular}{|c|c|c|c|}
\hline Respondent alone & $\begin{array}{l}1.05(1.02- \\
1.07)\end{array}$ & 0.001 & $\begin{array}{l}1.02(1.01- \\
1.03)\end{array}$ \\
\hline Respondent and Spouse & $\begin{array}{l}1.06(1.04- \\
1.08)\end{array}$ & 0.000 & $\begin{array}{l}1.00(0.98- \\
1.02)\end{array}$ \\
\hline
\end{tabular}




\begin{tabular}{|c|c|c|c|c|}
\hline Characteristics & $\operatorname{IRR}(95 \% \mathrm{Cl})$ & significance & $\operatorname{alRR}(95 \% \mathrm{Cl})$ & significance \\
\hline Spouse alone & Reference & & & \\
\hline \multicolumn{5}{|l|}{ Media exposure } \\
\hline Exposed to media & $\begin{array}{l}1.13(1.11- \\
1.15)\end{array}$ & 0.000 & $\begin{array}{l}1.03(1.01- \\
1.05)\end{array}$ & 0.002 \\
\hline \multicolumn{5}{|l|}{ Ethnicity } \\
\hline Hausa/Fulani & Reference & & & \\
\hline Yoruba & $\begin{array}{l}1.13(1.10- \\
1.16)\end{array}$ & 0.000 & $\begin{array}{l}1.03(1.01- \\
1.07)\end{array}$ & 0.315 \\
\hline Igbo & $\begin{array}{l}1.15(1.13- \\
1.18)\end{array}$ & 0.000 & $\begin{array}{l}1.05(1.01- \\
1.11)\end{array}$ & 0.032 \\
\hline Others & $\begin{array}{l}1.09(1.04- \\
1.15)\end{array}$ & 0.001 & $\begin{array}{l}1.01(0.98- \\
1.04)\end{array}$ & 0.038 \\
\hline \multicolumn{5}{|l|}{ Religion } \\
\hline Islam & Reference & & & \\
\hline Christians & $\begin{array}{l}1.08(1.07- \\
1.10)\end{array}$ & 0.000 & $\begin{array}{l}0.99(0.96- \\
1.02)\end{array}$ & 0.254 \\
\hline Others & $\begin{array}{l}1.03(0.93- \\
1.14)\end{array}$ & 0.554 & $\begin{array}{l}0.95(0.84- \\
1.07)\end{array}$ & 0.201 \\
\hline \multicolumn{5}{|l|}{ Marital Status } \\
\hline Never married & $\begin{array}{l}1.01(0.94- \\
1.07)\end{array}$ & 0.864 & + & \\
\hline Living with a spouse & $\begin{array}{l}1.01(0.97- \\
1.06)\end{array}$ & 0.549 & & \\
\hline Widowed/Divorced/Separated & Reference & & & \\
\hline \multicolumn{5}{|l|}{ Household Wealth status } \\
\hline Low & Reference & & & \\
\hline Middle & $\begin{array}{l}1.09(1.07- \\
1.11)\end{array}$ & 0.000 & $\begin{array}{l}1.02(1-00- \\
1.04)\end{array}$ & 0.026 \\
\hline Richest & $\begin{array}{l}1.17(1.15- \\
1.19)\end{array}$ & 0.000 & $\begin{array}{l}1.03(1.01- \\
1.06)\end{array}$ & 0.034 \\
\hline \multicolumn{5}{|l|}{ Children ever-born } \\
\hline 1 or 2 births & $\begin{array}{l}1.04(1.02- \\
1.06)\end{array}$ & 0.000 & $\begin{array}{l}1.01(0.98- \\
1.04)\end{array}$ & 0.204 \\
\hline
\end{tabular}




\begin{tabular}{|c|c|c|c|c|}
\hline Characteristics & $\operatorname{IRR}(95 \% \mathrm{Cl})$ & significance & $\operatorname{alRR}(95 \% \mathrm{Cl})$ & significance \\
\hline 3 or 4 births & $\begin{array}{l}1.04(1.02- \\
1.06)\end{array}$ & 0.000 & $\begin{array}{l}1.01(0.98- \\
1.03)\end{array}$ & 0.378 \\
\hline More than 4 births & Reference & & & \\
\hline \multicolumn{5}{|c|}{ Current employment status } \\
\hline Employed & $\begin{array}{l}1.03(1.01- \\
1.05)\end{array}$ & 0.001 & $\begin{array}{l}0.97(0.93- \\
1.01)\end{array}$ & 0.074 \\
\hline \multicolumn{5}{|c|}{$\begin{array}{l}\text { Spouse current employment } \\
\text { status }\end{array}$} \\
\hline Employed & $\begin{array}{l}1.04(1.02- \\
1.06)\end{array}$ & 0.000 & $\begin{array}{l}1.04(1.01- \\
1.09)\end{array}$ & 0.039 \\
\hline \multicolumn{5}{|l|}{ Residence } \\
\hline Urban & $\begin{array}{l}1.09(1.07- \\
1.11)\end{array}$ & 0.000 & $\begin{array}{l}1.01(0.99- \\
1.03)\end{array}$ & 0.154 \\
\hline \multicolumn{5}{|c|}{ Place of antenatal care } \\
\hline Health facility & $\begin{array}{l}1.42(1.35- \\
1.49)\end{array}$ & 0.000 & $\begin{array}{l}1.37(1.29- \\
1.44)\end{array}$ & 0.000 \\
\hline \multicolumn{5}{|c|}{ Provider of ANC assistance } \\
\hline Skilled provider & $\begin{array}{l}1.19(1.16- \\
1.22)\end{array}$ & 0.000 & $\begin{array}{l}1.10(1.07- \\
1.12)\end{array}$ & 0.000 \\
\hline \multicolumn{5}{|c|}{ Household head sex } \\
\hline Male & $\begin{array}{l}1.03(1.01- \\
1.05)\end{array}$ & 0.016 & $\begin{array}{l}1.00(0.98- \\
1.03)\end{array}$ & 0.390 \\
\hline \multicolumn{5}{|l|}{ Wanted Last child } \\
\hline Then & $\begin{array}{l}1.03(0.98- \\
1.07)\end{array}$ & 0.243 & + & \\
\hline Later & $\begin{array}{l}1.01(0.97- \\
1.06)\end{array}$ & 0.576 & & \\
\hline Never & Reference & & & \\
\hline \multicolumn{5}{|l|}{ Family Mobility } \\
\hline Less stable 0-4yr & $\begin{array}{l}1.04(1.03- \\
1.06)\end{array}$ & 0.000 & $\begin{array}{l}1.00(0.98- \\
1.02)\end{array}$ & 0.472 \\
\hline \multicolumn{5}{|c|}{ Have health Insurance } \\
\hline Yes & $\begin{array}{l}1.09(1.05- \\
1.14)\end{array}$ & 0.000 & $\begin{array}{l}1.01(0.96- \\
1.06)\end{array}$ & 0.338 \\
\hline
\end{tabular}




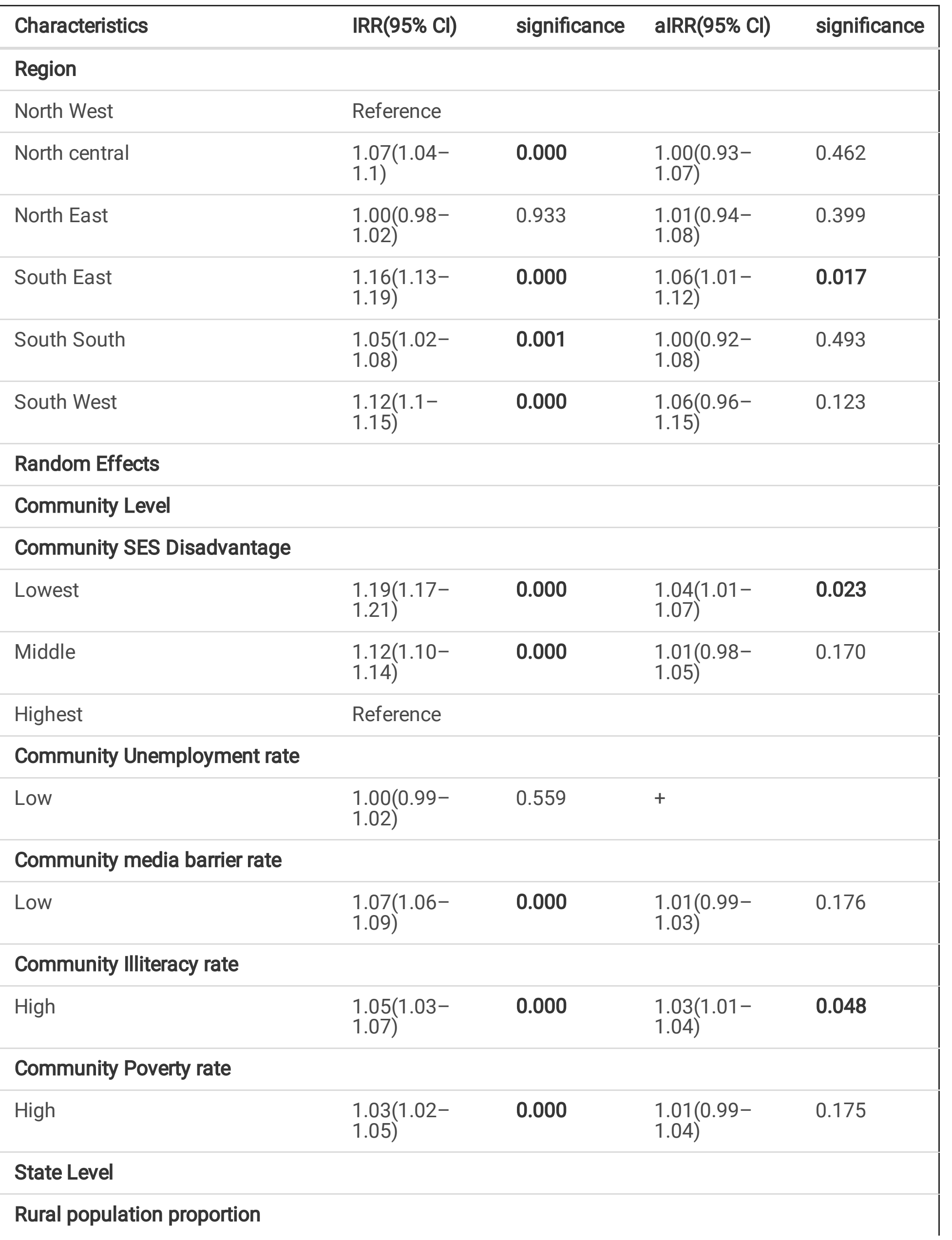




\begin{tabular}{|c|c|c|c|c|}
\hline Characteristics & $\operatorname{IRR}(95 \% \mathrm{Cl})$ & significance & $\operatorname{alRR}(95 \% \mathrm{Cl})$ & significance \\
\hline Low & $\begin{array}{l}1.09(1.07- \\
1.11)\end{array}$ & 0.000 & $\begin{array}{l}1.03(1.01- \\
1.06)\end{array}$ & 0.034 \\
\hline Middle & $\begin{array}{l}0.91(0.97- \\
1.01)\end{array}$ & 0.160 & $\begin{array}{l}0.95(0.91- \\
1.00)\end{array}$ & 0.053 \\
\hline High & \multicolumn{4}{|l|}{ Reference } \\
\hline \multicolumn{5}{|l|}{ Model Estimates } \\
\hline \multicolumn{5}{|c|}{$\begin{array}{l}\text { State level: MIRR = } 1.05(1.04-1.08), \mathrm{VPC}(\mathrm{ICC})=0.09(0.05-0.17), \% \text { Explained variation }=56.2(29.9- \\
77.3)\end{array}$} \\
\hline \multicolumn{5}{|c|}{$\begin{array}{l}\text { Community Level: MIRR = } 1.02(1.01-1.07), \mathrm{VPC}(\mathrm{ICC})=0.10(0.05-0.33), \% \text { Explained variation }= \\
49.0(28.6-75.4)\end{array}$} \\
\hline \multicolumn{5}{|c|}{$\begin{array}{l}\text { IRR Incidence Rate Ratio, MIRR Median Incidence Rate Ratio; Crl Credible Interval; VPC variance } \\
\text { partition coefficient, +dropped from adjusted model }\end{array}$} \\
\hline
\end{tabular}

\section{Clustering of ANC components received}

Figure 8 shows clustering in of components of ANC received. It shows that pregnant women who received information on HIV, are likely to receive information on danger sign warning and get tetanus injection while having urine test, blood pressure and blood test formed a cluster and finally having IPD and IPTp formed another cluster. As shown, there are lower chances of having IPD and IPTp compared with the other components.

\section{Discussions}

This study was designed to assess the level of ANC components offered to pregnant women in Nigeria during ANC contacts in Nigeria and the associated factors. We found that only one in every twenty pregnant women received all the 9 ANC components available for this study. The ANC components are having blood pressure measured, receiving tetanus injection, had a urine test, had a blood test, given an iron supplement, reported taking three or more doses of IPTp, IPD, and told about danger signs and HIV/PMTCT. In comparison with the findings of Fagbamigbe et al, the proportion of women who received all ANC components offered remained low. The authors had assessed the quality of ANC in Nigeria using data collected in the same setting five years earlier, the authors found that only $12 \%$ of the respondents had the 7 critical components of ANC [15]. One would have expected a much higher tremendous improvement in the quality of ANC services following the rejuvenation of Nigeria's primary healthcare system in recent times through the World Bank sponsored "Nigerian State Health Investment Programme (NSHIP)" [29]. The low level is despite the well-known fact that the quality of ANC care significantly reduces mortality, morbidity, and disabilities and improves health maternal and child health outcomes [30-32]. Globally, ANC and its compliance remain the safest approach for safe motherhood [4-6]. 
Although at least $79 \%$ of the women received each of the 7 of the 9components of ANC during the last pregnancy, only $24 \%$ and $22 \%$ each had IPTp and IPD respectively. Nigeria is a malaria-infested country, despite that the disease is preventable, treatable, and curable, with over $25 \%$ of the annual $25-30$ million pregnant women in malaria-endemic areas in Africa [33], yet less than a quarter received the prescribed doses of IPTp. It is worrisome that only a quarter of pregnant women in Nigeria had IPTp during their last pregnancy and only $17 \%$ of women with a live birth in the 2 years preceding the survey reported having at least 3 doses of IPTp [13]. Malaria is one of the foremost public health problems in the country. Nigeria alone accounts for a quarter of the burden of malaria in Africa. This was why the Federal Ministry of Health recommended that all pregnant women should have at least three doses of IPTp in the course of each pregnancy. There is an urgent need to increase the uptake of IPTp in Nigeria. The low level of pregnant women offered IPD resonates with the little attention paid to the fight against intestinal parasites during pregnancy in Nigeria, the long clamour for its use to address this public health problem nothwithstanding[34, 35]. Nigeria just like most Sub-Saharan Africa countries harbours the greatest proportion of global intestinal parasitic infections largely as a result of her socioeconomic and environmental challenges[36-38].

Socio-demographic and economic characteristics pose a significant influence on the number of ANC components offered to pregnant women. In this study, similar to the findings of other studies in LMIC, various characteristics including respondents' age, education, and economic class significantly influenced the having adequate quality of ANC components [18, 39-41]. In particular, pregnant women with higher educational attainment had a higher likelihood of receiving a higher number of components of ANC relative to those with no education. Similarly, there is a higher likelihood of receiving all components among pregnant women aged 40 to 49 years relative to those aged 15 to 19 years just as those from households in the wealthiest quintile had higher chances of receiving complete ANC components. Although education mediates in choice of place of ANC services [39, 42], and more educated women are more likely to belong to households in wealthier quintiles [27] and initiate ANC earlier [31, 43], it is not certain if different categories of women attending the same facility received different components based on their educational status. This will require further studies. Women with better-educated spouses also have significantly higher chances of receiving all the components.

Women who make decisions on their healthcare utilization alone or jointly with the spouse had significantly higher chances of getting more components than those whose spouses are the only decision-maker of the women's health care. Our finding is in agreement with existing literature [39, 42, 44]. This ease of decision making on women's healthcare utilization can greatly influence the timeliness of ANC service uptake, the number of ANC contacts made, and consequently, the quality of ANC services received.

Although insignificant in the multivariable model, the proportion that received all the components among the Christians nearly tripled the proportion among the Muslim women. This might be ascribed to the fact that Christians provide mission delivery and care and thereby provide the components better than others. Also, Christians may often receive double ANC service. Most times, Christian pregnant women receive 
ANC services from both the mission houses as well as other government facilities[45, 46]. This could have increased the chances of better quality among Christian women than other women. Nonetheless, the differences between religious groups could be largely due to the states of residence of the respondent as most Muslim women reside in the northern states while Christian women are mostly from the southern states.

Another significant variable to the receipt of a higher number of ANC components is ethnicity. A higher number of components were commoner among the Igbo women than the Hausa/Fulani women but insignificantly different when compared with the Yoruba women[31, 43]. From this study, there were wide variations in the adequacy of components received by these background characteristics. Although insignificant in the adjusted model, receipt of higher numbers of the component was higher among pregnant women who have less mobility, did not experience violence and who has health insurance. Women with health insurance cover have a higher likelihood of having quality ANC services. This finding points to the fact that the components are mostly offered when the ANC services are covered by insurance than when they are provided free of charge.

We found that pregnant women from the same clusters and communities have a similar likelihood of receiving similar components. Those from the least disadvantaged social-economic status communities had a preponderance of receiving a higher number of ANC components than those from the most disadvantaged communities. Pregnant women from communities with a low proportion of illiterate women also had higher chances of receiving a higher number of components just as those from states with a low rural population received higher numbers of components. The skill and distance of ANC providers to a community can greatly influence the adequacy of ANC components offered [47].

There were wide variations in the completeness of components received by background characteristics and the state of origin of the women. There is a need to overturn the inadequacies and eliminate disparities and variations in receiving all the ANC components. These variations and disparities could contribute to poor pregnancy outcomes [20]. Of significance in this study, are the type of health facility where ANC services were sourced and the skill of the ANC service provider. Pregnant women who attended institutional health care services including public and private standard hospitals and those attended to by qualified nurses and doctors had a higher level of receiving a higher number of ANC components. Similar studies have associated these factors with the quality of ANC services $[20,23,41$, 48]. This association could be ascribed to better knowledge on the importance of the components among trained nurses, midwives, and doctors than the other unskilled providers who are usually found in noninstitutional facilities[10].

We found that the number of ANC visits made during pregnancy and the timing of the first ANC visit were both significantly associated with the number of ANC components received. The earlier the initiation of ANC contacts, the higher the prevalence of having a higher number of ANC components. Fagbamigbe et al. had already suggested that early initiation of ANC contacts and having a sufficient number of contacts may increase the number of components of ANC received [49]. Also, the higher the number of 
ANC contacts made, the higher the prevalence of having a higher number of ANC components. This is intuitive as initiating ANC contact early during the first trimester could increase the proportion of pregnant women making eight or more visits and the quality of ANC received will increase proportionately. Our finding is corroborated by findings of earlier studies that the high quality of ANC services is a direct consequence of early initiation and the sufficient number of ANC contacts $[20,23,41,48]$. Literature is replete that ANC services significantly promote maternal and child health outcomes and by extension, reduction of maternal and child mortalities $[20,39,50,51]$.

It is striking that all the states in the Northern regions of Nigeria except Kwara and FCT had less than the national average that received all the 9 components of ANC. The average proportion who received all the 9 components in the North Central, Northeast, and North West were $5 \%, 3 \%$, and $2 \%$ respectively. The prevalence in Kebbi State was $0.3 \%$ while Borno had $0.1 \%$. Similar geographical variations in the quality of ANC has been documented[10]. States with the highest prevalence of ANC attendance had the highest prevalence of women receiving all components and vice versa. Although the prevalence is generally poor in Nigeria, the States with low ANC utilization and low prevalence of having all ANC component should take a cue from states such as Lagos, Ogun, Abia, and Anambra with better indicators. Additionally, we found clustering among having talks on HIV prevention and transmission, talk on danger signs and having tetanus injection while having urine test, blood pressure and blood test formed a cluster and finally having IPD and IPTp formed another cluster. There were distinct variabilities in the clustering of these ANC components.

\section{Study Strength And Limitation}

A major limitation of this study is the use of secondary data that prevented us from a detailed assessment of health system factors. Besides, we couldn't assess within-facility variations due to limited data. Also, our data was supplied by respondents without any way of considering facility-level data and facility-level factors occasioned by the secondary nature of the data used. The data were based mostly on respondents' ability to recall the number of ANC contacts during pregnancy, except few cases that were found on ANC cards. A recall bias is not unlikely. Caution should be exercised when interpreting our findings. The identified factors in this study are only associated with the number of ANC components received and should not be taken for causes of the number of ANC components received as the study was only cross-sectional in design. However, our findings are generalizable as the sample was nationally representative of the Nigerian population. More so, the data source has been reported to use rigorously tested collection tools, procedures, and trained personnel on questionnaire administration. The computationally intensive methods used for data analysis guarantees the accuracy and reliability of our estimates. This study is probably the first to explore the clustering of ANC components received by pregnant women in Nigeria.

\section{Conclusions}


The overall prevalence of receiving all the 9 components of ANC received during ANC contacts in Nigeria is poor. There is a need to ensure that all pregnant women receive an adequate and optimal number of ANC components. Different factors influenced the number of ANC components received. Notable among them is the institution and skill of the ANC provider, education, and social-economic status of the women. The study shows a strong relationship between timeliness of ANC initiation and having a minimum of 8 ANC contacts as they both increased the adequacy of ANC components received during the contacts. Although there are some states with high ANC utilization but inadequate ANC components. Our study suggested that early initiation of ANC during the first trimester, and having the recommended number of ANC contacts are critical to having all ANC components, which in turn ensures that a pregnant woman and her unborn child take optimal advantage of ANC services.

\section{Recommendations}

There is a need to ensure that all pregnant women receive all ANC components. Stakeholders should increase supplies, train, and create awareness among ANC providers and pregnant women. States such as Sokoto should understudy what works in states such as Abia, Anambra, Enugu, and Oyo with high ANC utilization and a high level of adequate ANC components received by pregnant women. We recommend a timely initiation of ANC services alongside the sufficient number of ANC contacts. There is a need to enhance the socio-economic status of women in terms of education and ensure women have autonomous decision-making power on their health care utilization.

\section{Abbreviations}

Adjusted Incidence Risk Ratio Ratio (aIRR),

Antenatal care (ANC),

Blood Pressure (BP),

Blood Test (BS),

Confidence Interval $(\mathrm{Cl})$,

Enumeration areas (EAs),

Federal Capital Territory (FCT),

Institutional Review Board (IRB),

Intestinal parasite drugs (IPD),

Intermittent preventive treatment in pregnancy (IPTp),

Iron Supplement (IRS) 
Local government areas (LGAs),

Low and Middle-Income Countries (LMIC),

Nigeria Demographic Health Survey (NDHS),

Pregnancy-related maternal mortality (PRMM),

Primary sampling unit (PSU),

Socioeconomic (SES), and

Sub-Sahara Africa (SSA),

Sustainable development goals (SDG)

Tetanus Injection (TET),

United Nations Children's Fund (UNICEF),

United Nations Population Fund (UNFPA),

Urine Test (US)

World Health Organization (WHO),

\section{Declarations}

\section{Ethics approval and consent to participate}

Ethics approval was obtained from the ICF Institutional Review Board, United States (Number FWA000008450) by the ICF International, the owners of the population-based secondary DHS datasets. We were granted full access to use the data by ICF International with authorisation letter 144644. Duly signed informed consent to participate was obtained from all consenting participants before the interview started. Further information on the data and ethical considerations are available at dhsprogram.com.

All methods were carried out in accordance with relevant guidelines and regulations.

\section{Consent for publication}

Not applicable

\section{Availability of data and materials}

The anonymized data is available in the public domain. The data supporting this article is available on request at www.dhsprogram.com and contact Bridgette Wellington, the Data Archivist. 


\section{Competing interests}

The authors declare that they have no competing interests.

\section{Funding}

The authors received no funding for this study.

\section{Authors' contributions}

AFF conceptualised the study, designed the study, AFF analysed the data, provided the visualization, and wrote the results. OSF contributed to interpretation and visualization of result. AFF, OSF, OGO, OOB, VS and JMN contributed to literature search, writing of introduction and discussion. All authors wrote the manuscript, read, and approved the manuscript.

\section{Acknowledgments}

The authors thank the ICF for granting access to the dataset.

\section{References}

1. WHO, UNICEF, UNFPA, UNPD, Group WB. Trends in maternal mortality: 1990 to 2015 . Publ WHO. 2015;:14.

2. United Nations. Sustainable Development Goals (SDG). Washington, DC; 2015. http://www.un.org/sustainabledevelopment/sustainable-development-goals/.

3. UNICEF. The State of the World's Children 2016: A fair chance for every child. New York: UNICEF; 2016. https://www.unicef.org/publications/index_91711.html.

4. Haruna U, Dandeebo G, Galaa SZ. Improving Access and Utilization of Maternal Healthcare Services through Focused Antenatal Care in Rural Ghana: A Qualitative Study. Adv Public Heal. 2019;2019:111.

5. Lassi ZS, Mansoor T, Salam RA, Das JK, Bhutta ZA. Essential pre-pregnancy and pregnancy interventions for improved maternal, newborn and child health. Reprod Health. 2014;11 Suppl 1.

6. Yeoh PL, Hornetz K, Dahlui M. Antenatal care utilisation and content between low-risk and high-risk pregnant women. PLoS One. 2016;11:1-17.

7. WHO. WHO Recommendation on Antenatal care for positive pregnancy experience. 2016. doi:ISBN 9789241549912.

8. Lincetto O, Mothebesoane-anoh S, Gomez P, Munjanja S. Antenatal Care: Opportunities for Africa's Newborns. New York; 2010. http://www.who.int/pmnch/media/publications/aonsectionlll_2.pdf.

9. Morhason-Bello IO, Fagbamigbe AF, Mumuni TO, Adesina OA, Abdus-Salam AR, Ifemeje A, et al. Evaluation of correct knowledge of key danger signs in pregnancy among antenatal clinic attendees at a tertiary health facility in Nigeria. Niger J Clin Pract. 2016;19:227-32. 
10. Ssetaala A, Nabawanuka J, Matovu G, Nakiragga N, Namugga J, Nalubega P, et al. Components of antenatal care received by women in fishing communities on Lake Victoria, Uganda; A cross sectional survey. BMC Health Serv Res. 2020;20:901. doi:10.1186/s12913-020-05739-9.

11. Fagbamigbe AF, Akanbiemu FA, Adebowale AS, Olumide AM, Korter G. Practice, Knowledge and Perceptions of Antenatal Care Services among Pregnant Women and Nursing Mothers in Southwest Nigeria. Int J Matern Child Heal. 2013;1:7-16.

12. National Population Commission [Nigeria] and ICF International. Nigeria Demographic and Health Survey 2013. Abuja, Nigeria; 2014.

13. National Population Commission(NPC)[Nigeria], ICF International. Nigeria Demographic and Health Survey 2018. Abuja, Nigeria, And Rockville, Maryland, USA; 2019.

14. Akanbiemu AF, Olumide MA, Fagbamigbe AF, Adebowale AS. Effect of Perception and Free Maternal Health Services on Antenatal Care Facilities Utilization in Selected Rural and Semi-Urban Communities of Ondo State, Nigeria. Br J Med Med Res. 2013;3:681-97.

15. Fagbamigbe AF, Idemudia ES. Assessment of quality of antenatal care services in Nigeria: evidence from a population-based survey. Reprod Health. 2015;12:1-9. doi:10.1186/s12978-015-0081-0.

16. Miltenburg AS, Eem L van der, Nyanza EC, Pelt van S, Ndaki P, Basinda N, et al. Antenatal care and opportunities for quality improvement of service provision in resource limited settings: A mixed methods study. PLoS One. 2017;12:e0188279, 1-15. doi:10.1371/journal.pone.0188279.

17. Agho KE, Ezeh OK, Ogbo FA, Enoma Al, Raynes-Greenow C. Factors associated with inadequate receipt of components and use of antenatal care services in Nigeria: A population-based study. Int Health. 2018;10:172-81. doi:10.1093/inthealth/ihy011.

18. Joshi C, Torvaldsen S, Hodgson R, Hayen A. Factors associated with the use and quality of antenatal care in Nepal: A population-based study using the demographic and health survey data. BMC Pregnancy Childbirth. 2014;14:1-11.

19. Ekott MI, Ovwigho U, Ehigiegba A, Fajola A, Fakunle B. Perception of pregnant women about antenatal care in a cottage hospital in Port Harcourt, Nigeria. J Community Health. 2013;38:360-5.

20. Afulani PA, Buback L, Essandoh F, Kinyua J, Kirumbi L, Cohen CR. Quality of antenatal care and associated factors in a rural county in Kenya: An assessment of service provision and experience dimensions. BMC Health Serv Res. 2019;19:1-16.

21. Afulani PA. Rural/Urban and socioeconomic differentials in quality of antenatal care in Ghana. PLoS One. 2016;::e0117996.

22. WHO. WHO antenatal care randomized trial: manual for the implementation of the new model-WHO program to map best reproductive health practices. Geneva; 2002.

23. Nyamtema AS, Jong AB, Urassa DP, Hagen JP, van Roosmalen J. The quality of antenatal care in rural Tanzania: what is behind the number of visits? BMC Pregnancy Childbirth. 2012;12 December 2010.

24. Mansur AMSA, Rezaul KM, Mahmudul HM, Chowdhury S. Quality of Antenatal Care in Primary Health Care Centers of Bangladesh. J Fam Reprod Heal. 2005;8:175-81. 
25. Snijders TAB, Bosker RJ. Multilevel analysis: an introduction to basic and advanced multilevel modeling. 2nd edition. London: Sage; 2012. https://www.stats.ox.ac.uk/ snijders/mlbook.htm. Accessed 22 Jun 2019.

26. Larsen K, Merlo J. Appropriate Assessment of Neighborhood Effects on Individual Health: Integrating Random and Fixed Effects in Multilevel Logistic Regression. Am J Epidemiol. 2005;161:81-8. doi:10.1093/aje/kwi017.

27. Fagbamigbe AF, Bamgboye EA, Yusuf BO, Akinyemi JO, Issa BK, Ngige E, et al. The Nigeria wealth distribution and health seeking behaviour: evidence from the 2012 national HIV / AIDS and reproductive health survey. Health Econ Rev. 2015;5:e1-10.

28. Mohanty SK. Alternative wealth indices and health estimates in India. Genus. 2008;LXV:113-37.

29. Sato R, Belel A. Effect of performance-based financing on health service delivery: a case study from Adamawa state, Nigeria. Int Health. 2020.

30. Simkhada B, Teijlingen E, Porter M, Simkhada P. Factors affecting the utilization of antenatal care in developing countries: systematic review of the literature. J Adv Nurs. 2008;61:244-60.

31. Ali AS, Dero AA, Ali A, Ali BG. Factors affecting the utilization of antenatal care among pregnant women: A literature review. J Pregnancy Neonatal Med. 2018;02. doi:10.35841/neonatalmedicine.2.2.41-45.

32. Chimankar DA, Sahoo H. Factors influencing the utilization of maternal health care services in Uttarakhand. Stud Ethno-Medicine. 2011;5:209-16. doi:10.1080/09735070.2011.11886411.

33. Okafor IP, Ezekude C, Oluwole EO, Onigbogi OO. Malaria in pregnancy: A community-based study on the knowledge, perception, and prevention among Nigerian women. J Fam Med Prim Care. 2019;8:1359-64. doi:10.4103/jfmpc.jfmpc_295_18.

34. Umeh JC, Inyang-Etoh PC, Okpokam DC, Otu-Bassey IB. Malaria and hookworm co-infection and their effects on anaemia of pregnant women attending ante-natal clinic in University Teaching Hospital, Calabar, Nigeria. Asian J Med Sci. 2018;9:27-35. doi:10.3126/ajms.v9i3.19294.

35. Obiakor-Okeke PN, Tina CN, Agugo UA, Nkechi MO. The prevalence of intestinal parasites and anaemia among pregnant women attending antenatal clinic in Federal Medical Centre Owerri, Imo State, Nigeria. J Biol Agric Healthc. 2014;4:171-7. https://www.cabdirect.org/globalhealth/abstract/20153005829. Accessed 3 May 2021.

36. Wekesa AW, Mulambalah CS, Muleke Cl, Odhiambo R. Intestinal helminth infections in pregnant women attending antenatal clinic at kitale district hospital, Kenya. J Parasitol Res. 2014;2014.

37. Abaka-Yawson A, Sosu SQ, Kwadzokpui PK, Afari S, Adusei S, Arko-Mensah J. Prevalence and Determinants of Intestinal Parasitic Infections among Pregnant Women Receiving Antenatal Care in Kasoa Polyclinic, Ghana. J Environ Public Health. 2020;2020.

38. Tay SCK, Nani EA, Walana W. Parasitic infections and maternal anaemia among expectant mothers in the Dangme East District of Ghana. BMC Res Notes. 2017;10:1-9.

39. Gudu W, Addo B. Factors associated with utilization of skilled service delivery among women in rural Northern Ghana: A cross sectional study. BMC Pregnancy Childbirth. 2017;17:1-10. 
40. Singh K, Osei-Akoto I, Otchere F, Sodzi-Tettey S, Barrington C, Huang C, et al. Ghana's national health insurance scheme and maternal and child health: A mixed methods study. BMC Health Serv Res. 2015;15:108. doi:10.1186/s12913-015-0762-y.

41. Amoakoh-Coleman M, Ansah EK, Agyepong IA, Grobbee DE, Kayode GA, Klipstein-Grobusch K. Predictors of skilled attendance at delivery among antenatal clinic attendants in Ghana: A crosssectional study of population data. BMJ Open. 2015;5:e007810. doi:10.1136/bmjopen-2015-007810.

42. Paul PL, Pandey S. Factors influencing institutional delivery and the role of accredited social health activist (ASHA): a secondary analysis of India human development survey 2012. BMC Pregnancy Childbirth. 2020;20:445. doi:10.1186/s12884-020-03127-z.

43. Fagbamigbe AF, Idemudia ES. Barriers to antenatal care use in Nigeria: evidences from non-users and implications for maternal health programming. BMC Pregnancy Childbirth. 2015;15:1-10. doi:10.1186/s12884-015-0527-y.

44. Ghose B, Feng D, Tang S, Yaya S, He Z, Udenigwe O, et al. Women's decision-making autonomy and utilisation of maternal healthcare services: Results from the Bangladesh Demographic and Health Survey. BMJ Open. 2017;7:e017142. doi:10.1136/bmjopen-2017-017142.

45. Shambe IH, Pam VC, Enokela MA, Oyebode TA, Daru PH, Gyang MD, et al. Choice of place of antenatal care among women of reproductive age in a semiurban population in northcentral. Trop $J$ Obs Gynaecol. 2018;35:54-7. doi:10.4103/TJOG.TJOG.

46. Awotunde OT, Amole IO, Adesina SA, Adeniran A, Olaolorun DA, Durodola AO, et al. Pattern of Antenatal Care Services Utilization in a Mission Hospital in Ogbomoso South-west Nigeria. J Adv Med Pharm Sc. 2019;21:1-11.

47. Omo-Aghoja LO, Aisien OA, Akuse JT, Bergstrom S, Okonofua FE. Maternal Mortality and Emergency Obstetric Care in Benin City South-South Nigeria. J Clin Med Res. 2010;2:55-60.

48. Magoma M, Requejo J, Merialdi M, Campbell OMR, Cousens S, Filippi V. How much time is available for antenatal care consultations? Assessment of the quality of care in rural Tanzania. BMC Pregnancy Childbirth. 2011;11.

49. Fagbamigbe AF, Olaseinde $O$, Setlhare $V$. Sub-national analysis and determinants of numbers of antenatal care contacts in Nigeria: assessing the compliance with the WHO recommended standard guidelines. BMC Pregnancy Childbirth. 2021;21:1-19. doi:10.1186/s12884-021-03837-y.

50. Kanyangarara M, Munos MK, Walker N. Quality of antenatal care service provision in health facilities across sub-Saharan Africa: Evidence from nationally representative health facility assessments. $\mathrm{J}$ Glob Health. 2017;7.

51. McDonagh M. Is antenatal care effective in reducing maternal morbidity and mortality? Heal Policy Plan. 1996;11:1-15.

\section{Figures}




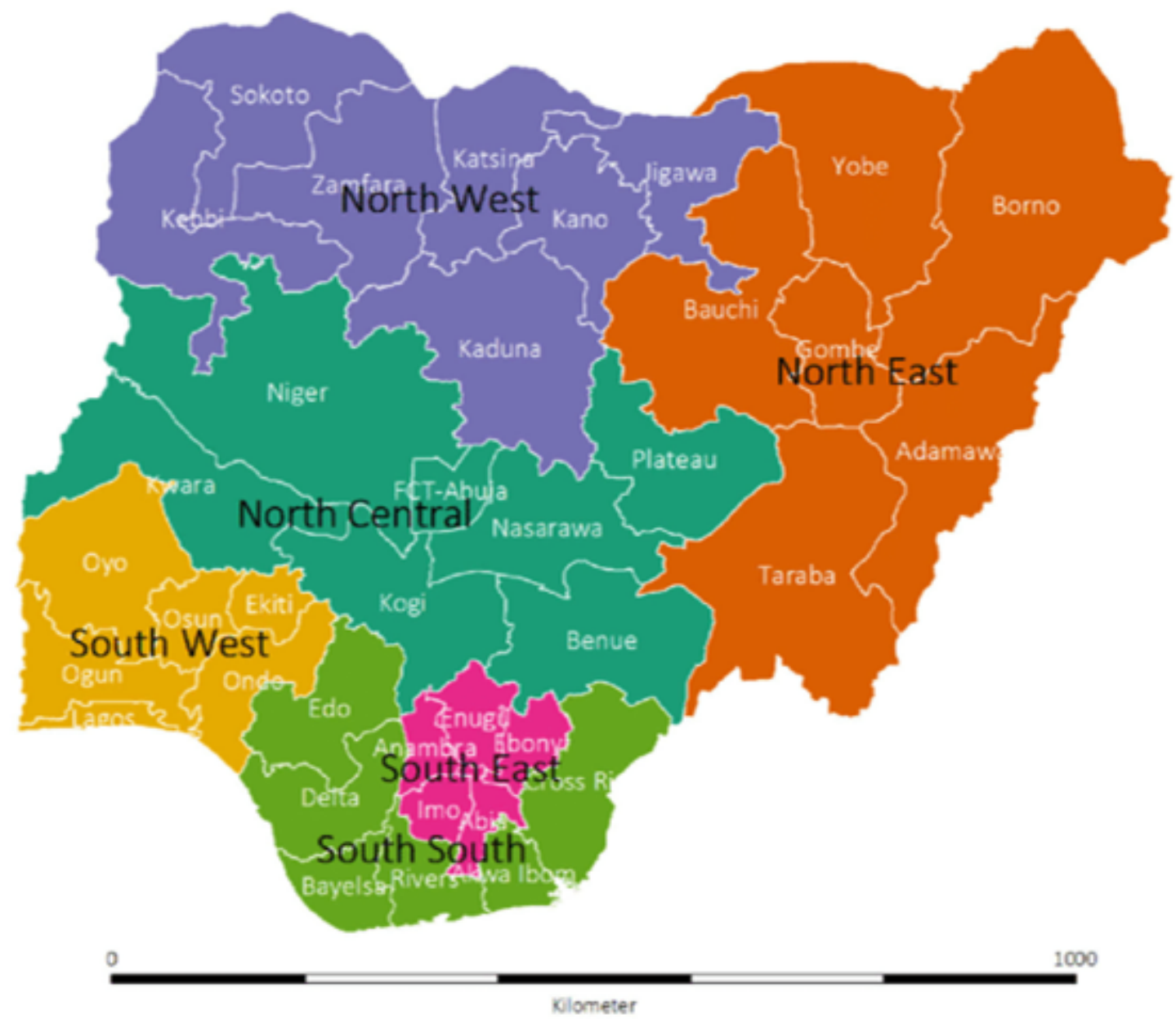

\section{Figure 1}

Map of Nigeria showing the 36 states and the federal capital territory (FCT), by the geopolitical regions/zones Note: The designations employed and the presentation of the material on this map do not imply the expression of any opinion whatsoever on the part of Research Square concerning the legal status of any country, territory, city or area or of its authorities, or concerning the delimitation of its frontiers or boundaries. This map has been provided by the authors. 


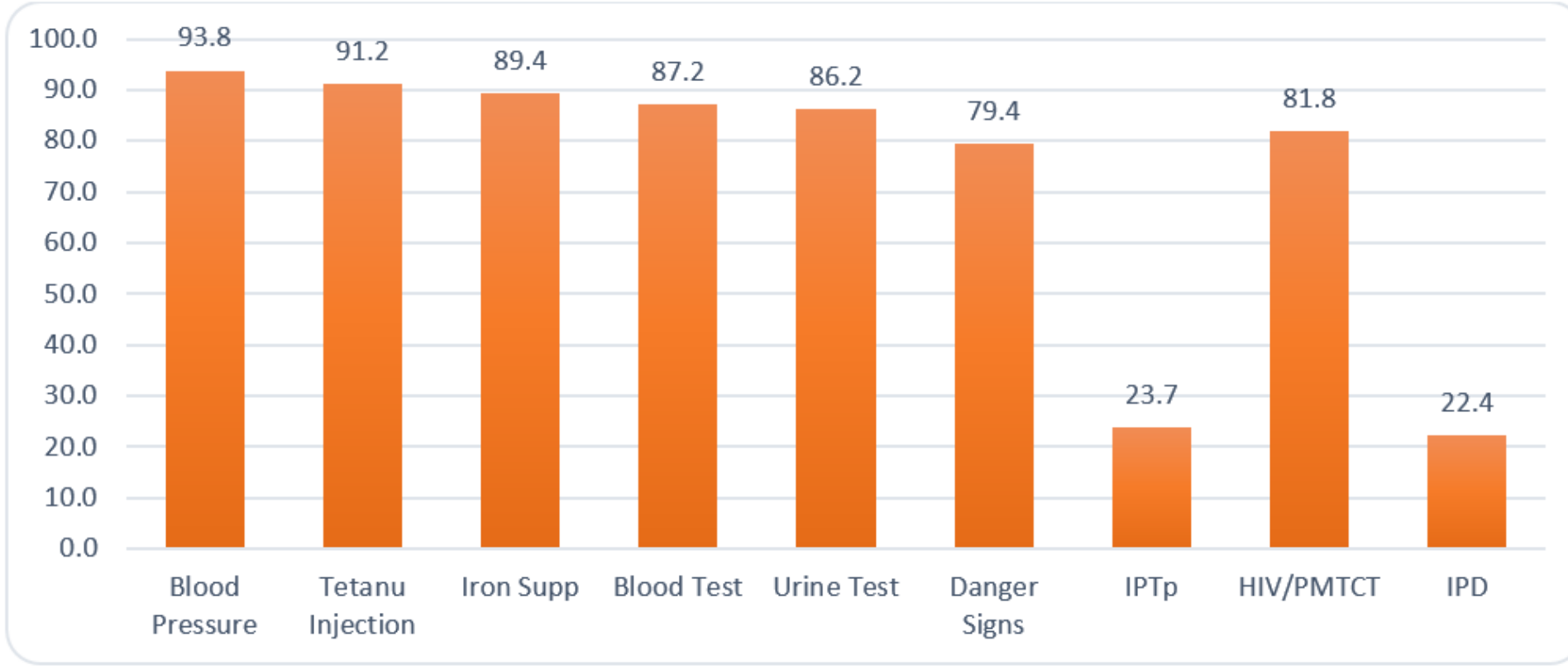

\section{Figure 2}

Distribution of ANC components received during the most recent pregnancy in Nigeria

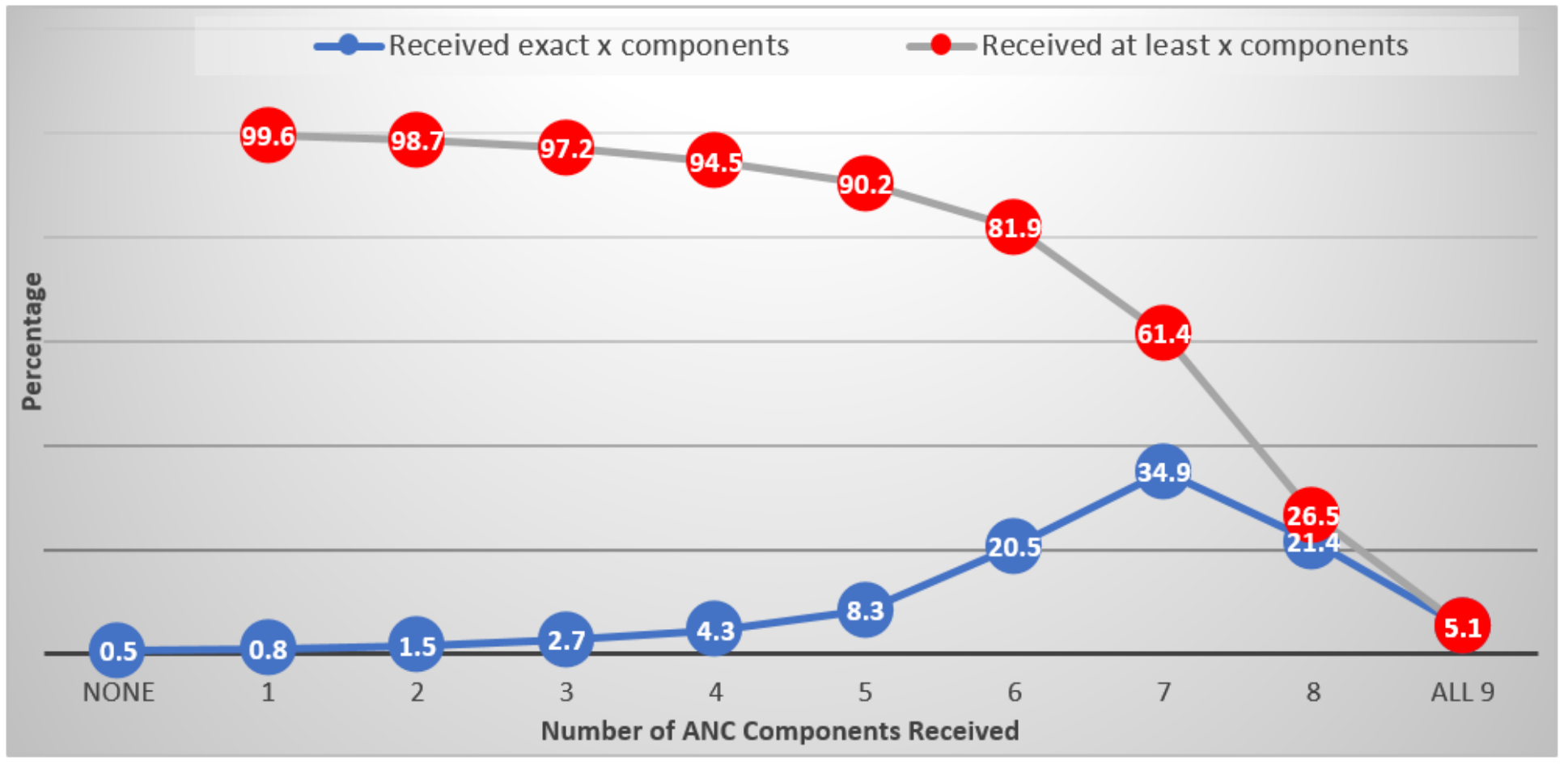

\section{Figure 3}

Distribution of ANC components received during pregnancy 


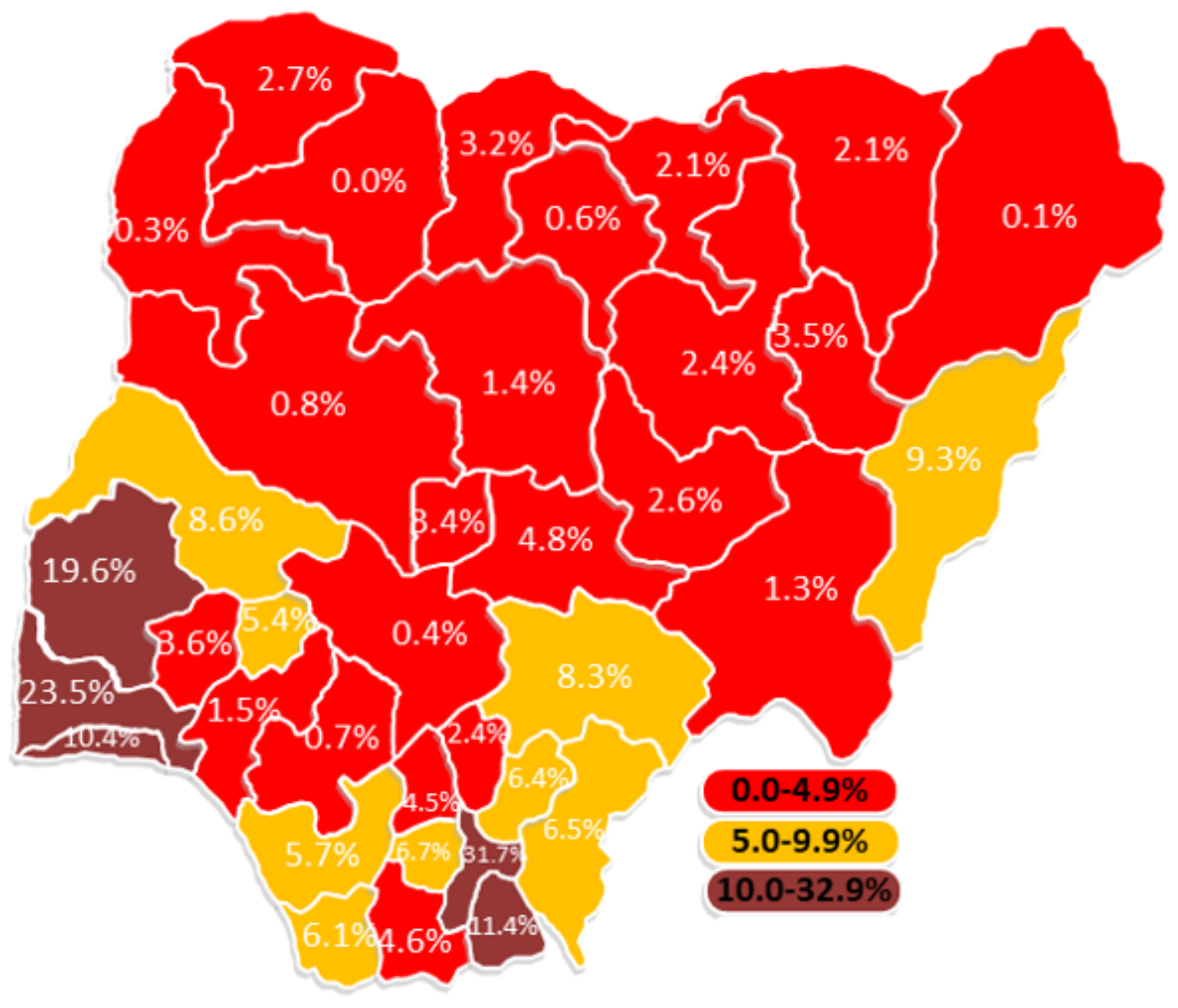

\section{Figure 4}

Distribution of the percentages of pregnant women offered all the 9 components of ANC during the most recent pregnancy by States in Nigeria Note: The designations employed and the presentation of the material on this map do not imply the expression of any opinion whatsoever on the part of Research Square concerning the legal status of any country, territory, city or area or of its authorities, or concerning the delimitation of its frontiers or boundaries. This map has been provided by the authors. 


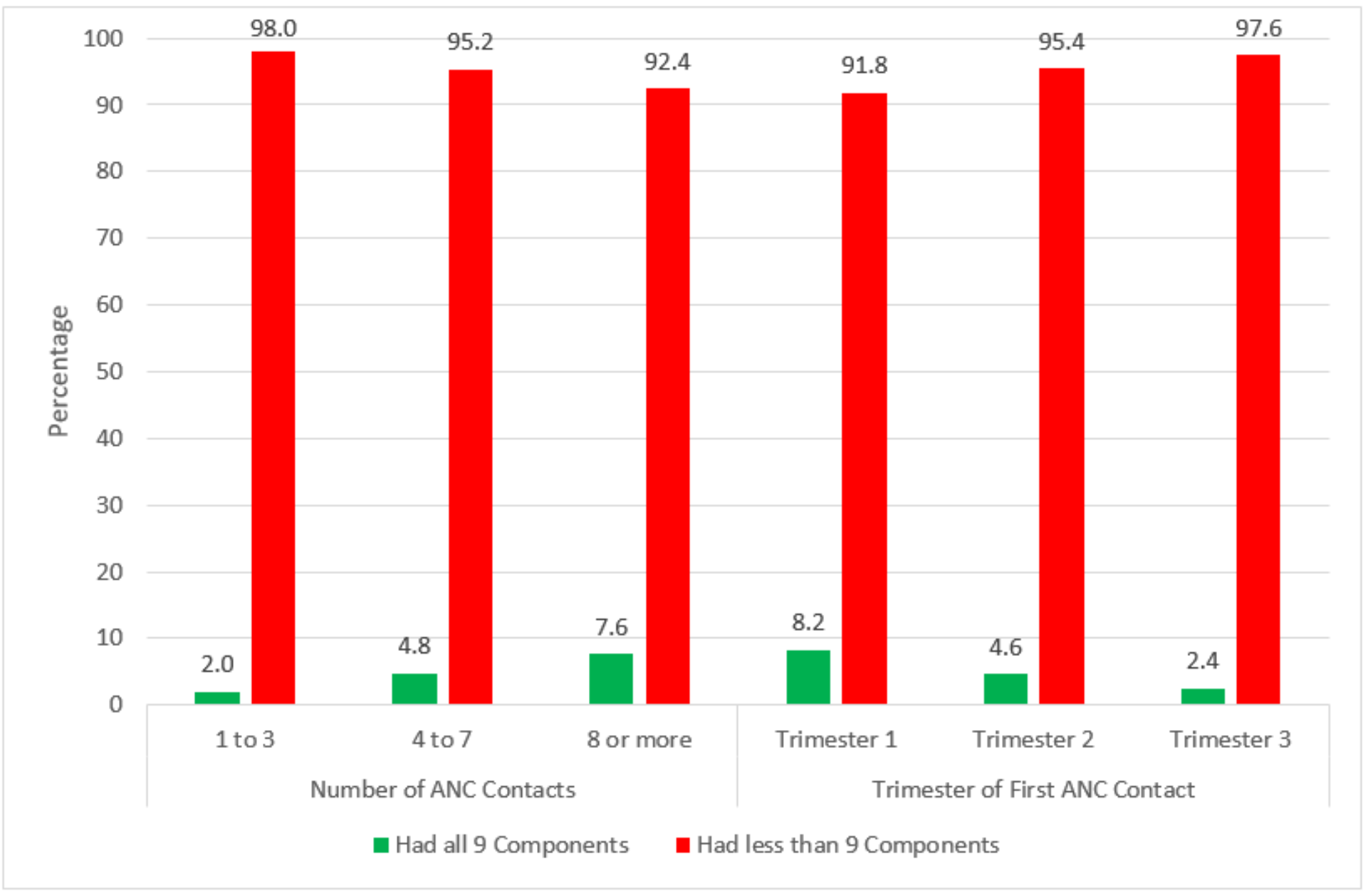

Figure 5

Relationship between the number of ANC visits, the timing of the first ANC visit, and receiving the 9 ANC components during the most recent pregnancy in Nigeria 

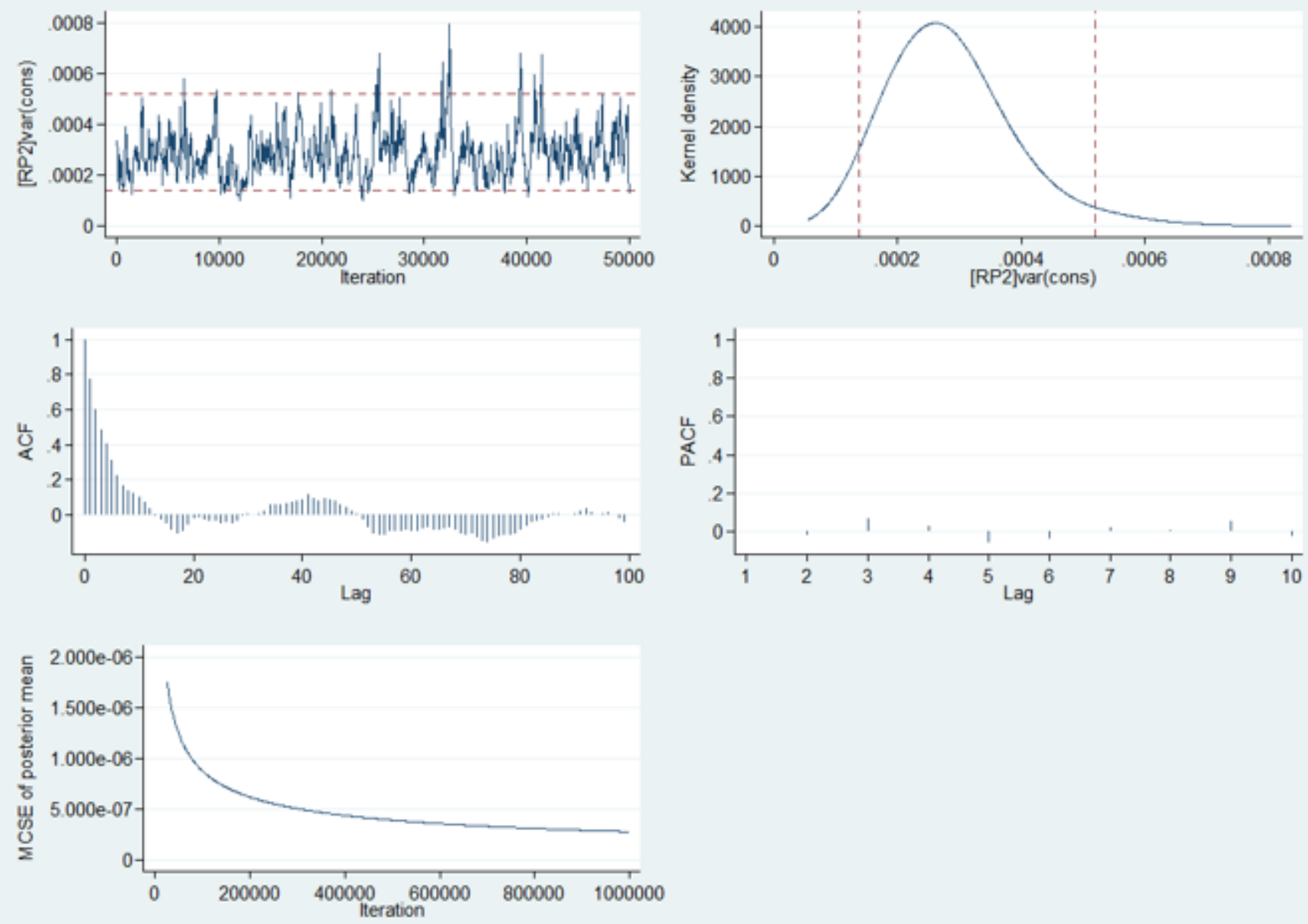

\section{Figure 6}

Five-way MCMC graphical diagnostics of the model at the community level 

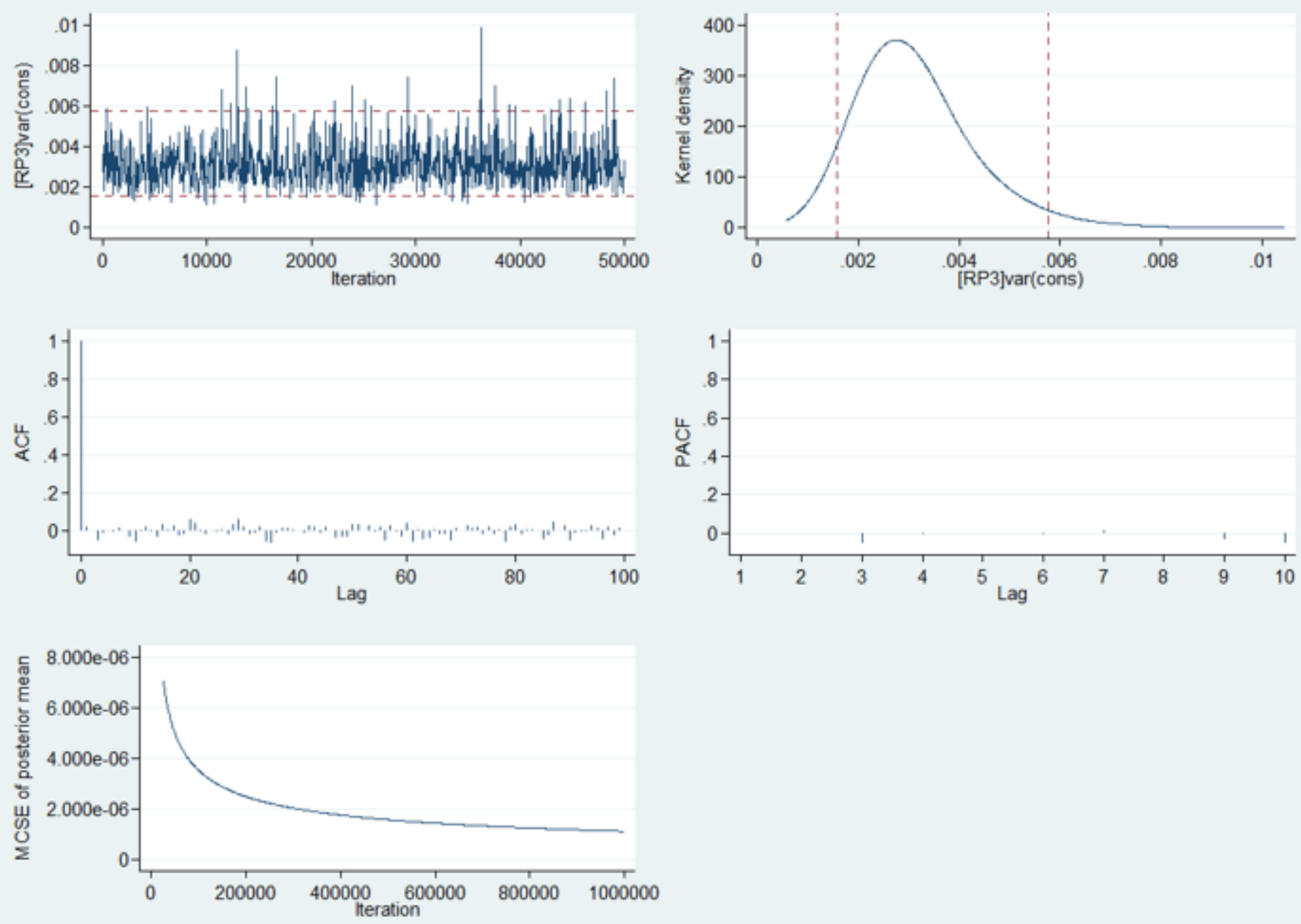

Figure 7

Five-way MCMC graphical diagnostics of the model at the state level

\section{Supplementary Files}

This is a list of supplementary files associated with this preprint. Click to download.

- SupplementaryTable1.docx 